\title{
Socio-Culture Impact of Child Marriage in Red Sea State
}

\author{
Ahmed Mohamed Bilal*, Etimad Gaafer Alfadil, Abdelrahman Mustafa Abdelrahman
}

Business Administration and Economic Department, Port Sudan Ahlia College, Port Sudan, Sudan

Email address:

ahmdblal@yahoo.com (A. M. Bilal)

${ }^{*}$ Corresponding author

To cite this article:

Ahmed Mohamed Bilal, Etimad Gaafer Alfadil, Abdelrahman Mustafa Abdelrahman. Socio-Culture Impact of Child Marriage in Red Sea State. Humanities and Social Sciences. Vol. 6, No. 4, 2018, pp. 121-124. doi: 10.11648/j.hss.20180604.14

Received: June 12, 2018; Accepted: July 13, 2018; Published: August 15, 2018

\begin{abstract}
The research aims to highlight cultural values and norms that are impeding practices related to child marriage in Red Sea State. The paper focuses on the concept and analytical approach to assess child marriage as one form of the various forms of marital relations. The paper analyzed the interaction relationship between early marriage practices in certain RSS localities with local community perceptions and traditional beliefs. The methodology to achieve the objectives were based on descriptive analytic approaches based on interviews, case studies and questionnaires for households in three localities namely, Sinkat, Haya and Toker. Research for early marriage are linked to the desire of relatives to preserve wealth, purity and fear of shame which girls may be subjected to with delayed marriage. It is seen as simple, non costly marriage which goes hand in hand with other values of rural areas. The impact of early marriage on social and cultural fabric was not clearly understood by locality inhabitant as $60 \%$ of the society reflected positively on the advantages of the phenomena. Fifty nine percent of the questionnaire recipient advocate that suitable marriage age is 12-18 years. The after-effects of early marriage on health and death during pregnancy are thought to decrease with education and nutrition. Evidence from localities reflect that women empowerment is low and as a consequence, social development factors are also affecting cultural fabric.
\end{abstract}

Keywords: Child Marriage, Sinkat, Haya, Toker, Phenomenon, Port Sudan, Red Sea State

\section{Introduction}

The Red Sea State lies on Eastern Sudan along the sea coast. The sea coast exceeds $740,000 \mathrm{~km}$, an area of about $218.000 \mathrm{~km}$. The population of the state exceeds $1,300,000$. The center of the state is the locality of Portsudan which represents all the ethnic groups of the Sudan.

The childhood rates in the ten localities of the state represent $47 \%$ of the total population (6640884 under eighteen years.). The percentage of disability with all its types (visual, audio, kinetic and learning difficulties). Represents $1.9 \%$ of the children in the state. Children marriage are not considered obvious disabilities, but hidden disabilities that destroy the quality of life in the most stage of the human life, i.e., the childhood stage.

Child marriage is any formal marriage or informal union where one or both parties are under18 years of age. Child marriage affects both boys and girls, but disproportionately affectsgirls. Each year, 15 million girls are married before the age of 18 , and that number isgrowing. Worldwide, 700 million women alive today were married before their 18th birthday and more than one in three girls are married before age of 15. Although the largest numbers of child brides are in South Asia, most of the countries with the highest prevalence of child marriage are in Africa. Sudan is among the African countries with a high prevalence of child marriage. In Sudan, $10.7 \%$ of women aged 15 to 49 were married before the age of 15 , and $38 \mathrm{~s} \%$ were married before the age of $18[1,2]$. Child marriage is a human rights violation affecting children's and women's rights to health, education, equality, non-discrimination, and freedom from violence and exploitation. Child marriage has harmful effects on young girls. Neither physically nor emotionally ready to become wives and mothers, child marriage exposes young girls to a wide range of health risks. The minds and bodies of young girls are physically unprepared for sexual activity and childbirth, increasing the risks of maternal health complications. Early pregnancy increases the risk of both 
maternal and child mortality. Added to that, girl brides are more likely to suffer domestic violence and marital rape. Child brides are rarely allowed to continue their education. With limited access to education and subsequent economic opportunities, child brides and their families are more likely to live in poverty.

In recent years, child marriage has received great attention on international and national development agendas. The UN Sustainable Development Goals, adopted in September 2015, include eliminating child marriage as a key target for advancing gender equality by 2030 . This goal may help sustain international attention and enhance political will at the national level in states with a high prevalence of child marriage. According to UNICEF's 2015 report A Profile of Child Marriage in Africa, the prevalence of child marriage has been slowly declining in Africa, but remains higher than the global average [3]. The fastest progress in reducing child marriage in Africa has been in the northern part of the continent.

Child marriage in Sudan has received heightened attention since late 2016 when it emerged as a recommendation from the UN after Sudan presented its Universal Periodic Report (United Nations 2016a; 2016b). In addition, the topic has recently come onto the public agenda in the context of reforming the Muslim Personal Law of 1991. That law sets the minimum age of marriage at tamyeez ("maturity"), which is 10 years old under the law. Furthermore, under the 1991 law, a woman needs a male guardian (a father, brother, or uncle) to contract her marriage. When the 1991 act was passed, the Islamic government of the time employed religious arguments to defend the legalization of child marriage. However, both government and civil society are now working for both legal and social change. In particular, the NGO Sudan Organization for Research and Development (SORD) has advocated for legalre form of the 1991 law's provisions on child marriage. The SEEMA Center has also turn edits attention to child marriage, particularly by working with victims. In December 2015, the Sudanese government launched the African Union campaign to end child marriage in Africa (African Union 2015b). In addition, the National Council for Child Welfare (NCCW), under supervision of the Sudan's minister of social welfare, has formulated a strategy for abandoning the practice, which is in process of being endorsed by the Cabinet of Ministers [3].

While there has been no legal reform of the Muslim Personal Law of 1991at the time of this report, the 2010 National Child Act defines "child" as a person below the age of 18. The 2010 law also includes provisions protecting children against all forms of discrimination, and, accordingly, it has been used as a platform to advocate for legal reform of the minimum age of marriage. However, this initiative has met resistance from religious conservative groups, who continue to argue that the practice of child marriage is in accordance with Sharia. On the other hand, women continue to fight to end child marriage in Sudan, pointing to its multiple harmful effects, both nationally and sub-nationally. In Red Sea State, a handful of local NGOs, community-based organizations, and the Red Sea State Child Welfare Council have engaged in continual awareness raising efforts on the harmful effects of child marriage. NGOs, community-based organizations, and the Red Sea State Child Welfare Council have engaged in continual awareness raising efforts on the harmful effects of child marriage [4].

This report investigates child marriage in Red Sea State, which is located in Sudan's eastern region. Red Sea State is one of Sudan's most gender conservative areas, and $32.2 \%$ of married women ages 20 to 49 were married before age 18 . Women in Red Sea State are frequently denied an education and pressurized to get married [4]. A staggering $89 \%$ of women there have been subjected to the harmful practice of female genital mutilation (FGM) in the name of tradition and culture [5].

This report explores local communities' attitudes toward child marriage in Red Sea State [6]. The research is an addition to the very limited number of studies on the current situation of women and children's rights in eastern Sudan (see Fadllala 2007; Agnes 1998; Khalid 2013). To date, there is no research tackling child marriage in Red Sea State [7, 8].

Several factors explain continuity of the practice of child marriage. First, it is a deeply rooted traditional practice. The most stated reason for practicing child marriage among respondents was tradition, called the silif in Red Sea State. Second, child marriage remains legal under the Muslim Personal Law of 1991, which means that any child marriage abandonment programs would contravene the law and would likely be aborted by religious groups. Against the backdrop of an authoritarian state that legalizes child marriage, it is difficult for anti-child marriage activists to advocate for the eradication of the practice without being seen as anti government. This means that awareness raising campaigns in Red Sea State take a "soft" approach; activists do not speak in what the Sudanese would term a "loud voice." Third, although there are both national and sub-national calls to end the practice, no stakeholders have issued a comprehensive strategy to support raising awareness on the harmful effects of child marriage. Finally, there is a link between education and child marriage, and the lack of educational facilities and the poor quality of education provided to girls creates an obstacle to ending the practice. Specifically, the curriculum in schools does not empower girls and their families to challenge gender discriminatory norms in order to protect girls against the harmful effects of child marriage. [9] It is interesting to note that while "poverty is a major factor underlying child marriage," according to UNFPA (2012, [10], and others, such as Girls Not Brides and Parsons et al. (2015), it was not among the most cited reason given for the continuation of the practice in Red Sea State [11]. The main reason stated by our respondents was control of girls' chastity, something which is inherently linked to gender discriminatory norms and tradition of protecting the family and tribe's honor. The findings in this report can be used to design interventions aimed at ending child marriage, especially interventions aimed at changing norms that continue to support the practice, as well as to promote the 
rights of girls and women to decide whom and when to marry. [12]

\section{Methods and Objectives}

a. The methodology of The research uses sampling survey data to explore the complex dimensions of the culturally sensitive topic of child marriage in Red Sea State. Data collection was undertaken from May to September 2016, using a clustered sampling survey. [13].

b. To understand the attitudes of the communities in the Red Sea State localities of Port Sudan and Haya towards the education and marriage of girls and boys;

c. to gain insight into the arguments for and decisionmaking process behind child marriage;

d. To cast light on the risks associated with child marriage, as perceived by the communities in Port Sudan and Haya;

e. To highlight the experiences of girls who continue education instead of getting married; and

f. To gain knowledge on how the local communities perceive awareness-raising campaigns to end child marriage.

\section{Results}

During the interviews we conducted, respondents stated that childhood ends between 10 and 14 years old for both girls and boys, depending on the physical growth of their bodies. One interviewee reported, "Childhood ends with puberty, and that differs among girls and between boys and girls." Signs of puberty are generally understood in Sudan to include, for example, the development of breasts and the start of the period for girls and the development of a deeper voice for boys. Very few individuals we interviewed defined a child as anyone younger than 18 , and all of those who did so were highly educated men or women. Even a young female university graduate stated that the defining line between childhood and adulthood is 15 years. It is evident that individuals in Red Sea State are not aware of the Red Sea State Child Law that defines a child as a person younger than 18 years. Rather, the perception of childhood is influenced by prevalent norms and traditions, as well as by the Beja group's religion. Further, interviewees considered both pubescent girls and boys to be ready for marriage.
Table 1. Age of marriage for boys in Red Sea State, Sudan, per the opinion of interviewees in researched communities.

\begin{tabular}{lll}
\hline $\begin{array}{l}\text { Age of marriage } \\
\text { for Boyes }\end{array}$ & $\begin{array}{l}\text { Females } \\
\text { (181 respondents)\% }\end{array}$ & $\begin{array}{l}\text { Males }(119 \\
\text { respondents)\% }\end{array}$ \\
\hline 7-10 years & 0 & 0 \\
11-14 years & 3.3 & 3.4 \\
15-17 years & 16.0 & 14.3 \\
Above 18 years & 80.7 & 82.4 \\
Total & 100.0 & 100.0 \\
\hline
\end{tabular}

Table 2. Age of marriage for girls in Red Sea State, Sudan, per the opinion of interviewees in researched communities.

\begin{tabular}{lll}
\hline $\begin{array}{l}\text { Age of marriage for } \\
\text { Boyes }\end{array}$ & $\begin{array}{l}\text { Females } \\
\text { (181 respondents)\% }\end{array}$ & $\begin{array}{l}\text { Males (119 } \\
\text { respondents)\% }\end{array}$ \\
\hline 7-10 years & 2.2 & 0.8 \\
11-12 years & 10.5 & 42.9 \\
13-15 years & 21.5 & 20.2 \\
16-17 years & 33.7 & 26.1 \\
18 years and above & 32.0 & 10.1 \\
Total & 100.0 & 100.0 \\
\hline
\end{tabular}

Tables 1 and 2 show the respondents' reports on the age at which most girls and boys in their communities get married. Perhaps unsurprisingly, they stated that boys in the communities marry at older ages than girls. More than $80 \%$ of male and female respondents interviewed asserted that boys in their communities marry above 18 years of age, yet several interviewees noted that girls are sometimes married as young as seven years old. In a group discussion, one woman stated, "Girls may (even) be betrothed the day of their birth."'15]. Although abetrothal at birth does not typically mean that the resulting marriage is consummated before puberty, the practice of contracting a girl's marriage at infancy reflects the low value of girls and women in the community, as it denotes that girls are a commodity that parents want to get rid of as soon as possible [15].

The second reason for child marriage shows the influence of traditions. The silif restricts the freedom of women and girls in the name of protecting the family and tribe's honor.

Approximately $40 \%$ of both male and female respondents to our survey confirmed that child marriage is done to comply with traditions. These respondents stood for maintaining traditions and were thus not yet ready to change or challenge prevalent norms. In short, although Red Sea State has experienced socio-economic development [1].

Table 3. Reasons for the child marriage of girls, based on respondents from Red Sea State, Sudan.

\begin{tabular}{lll}
\hline Reasons for child marriage & Females (181 respondents), \% & Males (119 respondents),\% \\
\hline Marriage is protection for girls & 61.9 & 52.9 \\
To comply with traditions & 39.2 & 41.2 \\
If girls get old they are stigmatized as agir or bayra & 10.5 & 32.8 \\
To have many children & 16.0 & 4.2 \\
To reduce family economic responsibilities & 7.7 & 13.4 \\
\hline
\end{tabular}

\section{Conclusion}

Child marriage in Red Sea State is a gender discriminatory practice perpetuated bypatriarchal norms. While both boys and girls in Red Sea State are often forced to marry during childhood, without being given the opportunity to choose whom or when to marry, the practice of child marriage affects girls more significantly than boys. 


\section{Recommendations}

The recommendations of the study will benefit researcher scholars and decision makers to design educational as well as social development programs to address early marriage consequences.

\section{References}

[1] Abdel Ati, H., S. Pavanello, S. Jaspars, A. A. Hashim, M. Idriss, and S. Pantuliano. 2011. City Limits: Urbanisation and Vulnerability in Sudan. London: Overseas Development Institute (ODI).https://www.odi.org/sites/odi.org.uk/files/odiassets/publications-opinion-files/6513.pdf.

[2] Abdel Halim, A. M. 2011. "A Home for Obedience: Masculinity in Personal Status for Muslims Law." Hawwa: Journal of Women of the Middle East and the Islamic World 9, no. 1: 194-214.

[3] Adams, M. 2007. “'National Machineries' and Authoritarian Politics: The Case of Cameroon." International Feminist Journal of Politics 9, no. 2: 176-197.

[4] African Union. 2003. Protocol to the African Charter on Human and People's Rights on the Rights of Women in Africa [Maputo http://www.achpr.org/files/instruments/womenProtocol]. protocol/achpr_instr_proto_women_eng.pdf.

[5] The Effects of Traditional and Religious Practices of Child Marriage on Africa's Socio-Economic Development: A Review of Research, Reports and Toolkits from Africa. African Union: Campaign to End Child Marriage in Africa. http://children.pan.org.za/sites/default/files/publicationdocume nts/Study on Tradition\%26 Religion Childmarriage Africa_report.pdf.

[6] The Republic of Sudan Launches the AU Campaign to End Child Marriage in Africa." Press release, Addis Ababa, 10 Dec. $\quad \mathrm{http}: / /$ endchildmarriagenow.org/wpcontent/uploads/2017/07/PR10-The-Republic-of-SudanLaunches-the-AU-Campaign-to-End-Child-Marriage-inAfrica.pdf.
[7] Al-Nagar, S., L. Tønnessen, and S. Bamkar. 2017. "Weak Law Forbidding Female Genital Mutilation in Red Sea State, Sudan." Sudan Working Paper no. 1, May. Bergen: Chr. Michelsen Institute.

https://www.cmi.no/publications/file/6229-weak-lawforbidding-female-genital-mutilation-in.pdf.

[8] Badri, N., and T. Al-Husseni. 2014. Exploring Stakeholders and Activists Perspectives on Effective Interventions For Combating Child Marriage. Sudan: Ahfad University for Women.

https://www.thefreelibrary.com/Exploring+stakeholders+and+ activists $\% 27+$ perspectives + on+interventions...-a0462983510.

[9] Backlund, H., and G. Blomqvist. 2014. "Protecting the Girl Child or Upholding Patriarchy: A Case Study of Child Marriage in the Cultural and Legal Context of Tanzania." Masters thesis, Lund University, Lund, Sweden.

[10] Bang, A. 2016. "Unfulfilled Hopes. The Quest for a Minimum Marriage Age in Yemen, 2009-2014.” CMI Report R 2016: 3. Bergen: CMI.

[11] BBC News. 2012. "Khartoum Expels Foreign Aid Agencies from Eastern Sudan." 1 June. http://www.bbc.com/news/world-africa-18296430.

[12] CEDAW Committee (Committee on the Elimination of Discrimination against Women). 1994. "General Recommendation No. 21: Equality in Marriage and Family Relations." In General Recommendations Adopted by the Committee on the Elimination of Discrimination against Women.

[13] De Silva-de-Alwis, R. 2008. "Child Marriage and the Law." Working paper, Legislative Reform Initiative Paper Series, Jan. New York: UNICEF. https://www.unicef.org/policyanalysis/files/Child_Marriage_a nd_the_Law (1).pdf.

[14] Equality Now. 2014. Protecting the Girl Child: Using the Law to End Child, Early, and Forced Marriage and Related Human Rights Violations. New York: Equality Now.

[15] Fadlalla, A. H. 2007. Embodying Honor: Fertility, Foreignness, and Regeneration in Eastern Sudan. Madison: University of Wisconsin Press. 